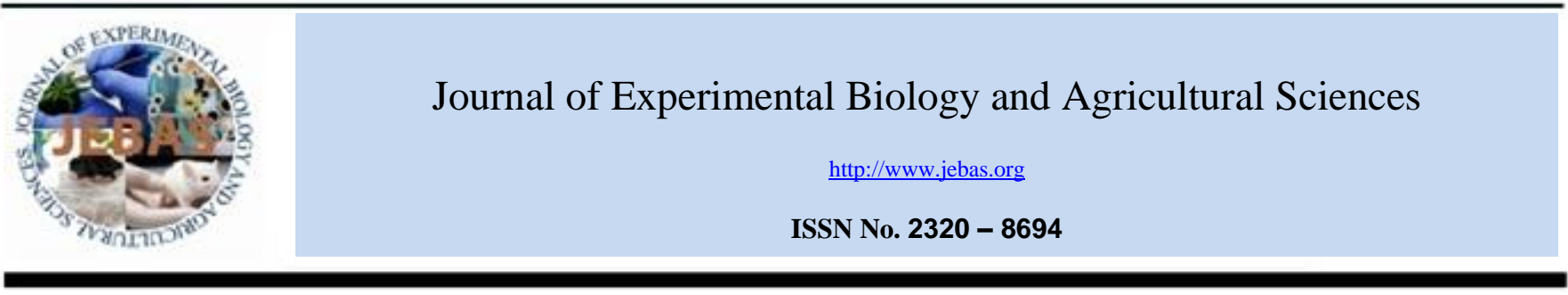

\title{
MENSTRUAL SYNDROME: SEVERITY, FREQUENCY AND SYMPTOMATOLOGY IN ADOLESCENT GIRLS OF QUETTA, PAKISTAN
}

\section{Faiza Hameed Jan ${ }^{1}$, Zil E Huma ${ }^{1}$, Nabeela Tariq ${ }^{1}$ and Naheed Sajjad ${ }^{2, *}$}

${ }^{1}$ Department of Zoology, Sardar Bahadur Khan Women's University, Quetta, Pakistan.

${ }^{2}$ Department of Biotechnology, Sardar Bahadur Khan Women's University, Quetta, Pakistan.

Received - February 21, 2016; Revision - March 08, 2016; Accepted - March 27, 2016

Available Online - April 25, 2016

DOI: http://dx.doi.org/10.18006/2016.4(2).128.132

\begin{abstract}
KEYWORDS
Dysmenorrhea

Menstruation

Menarche

Nausea

Quetta

ABSTRACT

The purpose of the study was to investigate the prevalence of menstrual characteristics, its frequency, age of menarche, symptomatology and factors associated with menstrual cycle. A total of 450respondentswere studied in 5 different government girls' schools of Quetta, Pakistan. Data was collected by close-ended questionnaire. Analysis of data was carried out by statistical software SPSS version 20 and significant association between different variables was analyzed by chi-square test. Significant association was reported between food and nausea, amount of blood flow and weakness and vice versa. The study revealed that the mean duration of blood flow was 5-7 days. It has been analyzed that there is a statistically significant relationship between type of pain and amount of flow $(\mathrm{p}<0.05)$. Among the studied group respondents, about $88.89 \%$ respondents reported dysmenorrhea. The study concludes that dysmenorrhea was prevalent and no significant association was found between dysmenorrhea and regularity of menstruation. Majority of the girls avoid physical activities like sports and exercise.
\end{abstract}

* Corresponding author

E-mail: naheedsaj@yahoo.com (Naheed Sajjad)

Peer review under responsibility of Journal of Experimental Biology and Agricultural Sciences.

Production and Hosting by Horizon Publisher India [HPI] (http://www.horizonpublisherindia.in/).

All rights reserved.
All the article published by Journal of Experimental Biology and Agricultural Sciences is licensed under a Creative Commons Attribution-NonCommercial 4.0 International License Based on a work at www.jebas.org.

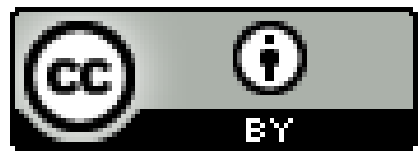




\section{Introduction}

The transition period from childhood to adulthood is called adolescence which is characterized by marked differentiation in endocrinal, emotional and mental growth. The adolescent period is a preparatory period for girls in which they get prepared physically and psychologically for safe motherhood. Being the "direct reproducers" of future generation, the healthy adolescent girl is not only responsible for her own health but for the health of the future population too (Agarwal \& Agarwal, 2010).

The distinctive feature of female puberty that signals the reproductive maturity is called menarche (El-Gilanya et al., 2005). Menstruation shows a remarkable range of variation, most of the women experience it at the age of 10-16 years. The age of menarche varies from population to population depending upon nutritional, geographical and environmental factors (Kaplowitz, 2006). Adolescent females suffer from various common problems such as premenstrual syndrome, amenorrhea and dysmenorrhea (Diaz et al., 2006). The social and educational life of $5-10 \%$ of the girls is interrupted by severe dysmenorrhea in their teens (Dawn, 1990).

According to the study conducted by Shersha et al. (1991) among 1600 women in Karachi, the prevalence of premenstrual syndrome (PMS) was 33\%.Within first 2 years of the menarche; the girls face comparatively more problems than those who have crossed this duration (Ziv et al., 1999). Reproductive tract infection (RTI) is also associated with menstrual hygiene. The unclean and improperly stored napkins used during menstruation can cause problems (El-Gilanya et

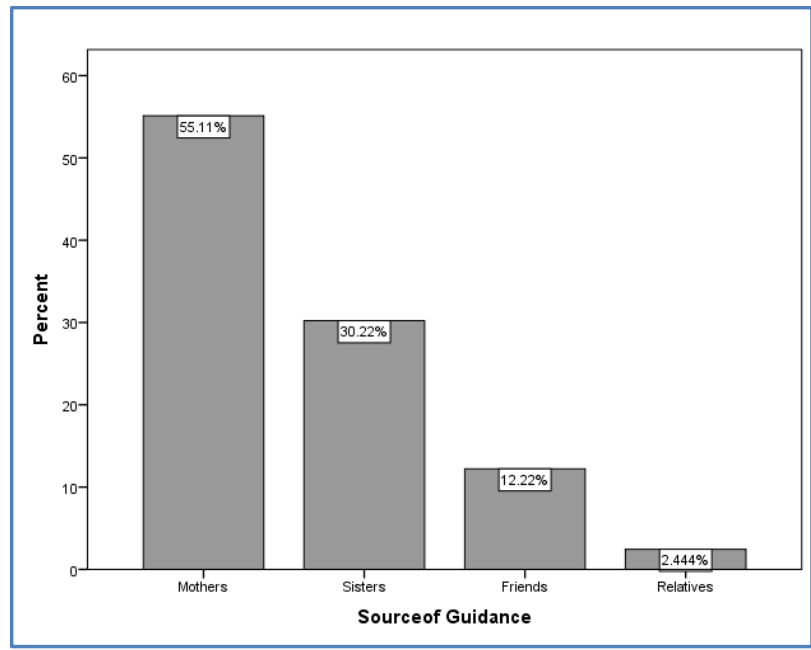

Figure 1 Source of menstrual guidance. al., 2005). The infection can be caused due to the use of unclean or dirty cloth napkins that result in the harboring of microorganisms in vagina. Improperly dried pads also provide favorable condition to the microbes in vaginal tract to cause infection (Paul, 2007). In India and Pakistan 98.5\% girls of both urban and rural areas used old cloth material for pads (Moaweds, 2001).Different prohibitions regarding menstruation has been observed such as, entry in the holy places, taking bath, changing cloths, combing hairs and restriction on particular food such as, potato, rice, onion, sugarcane, curd, milk and lassi etc. (Kaplowitz, 2006). Due to the importance of this syndrome, a study was designed to investigate the frequency, severity, symptomology about menstrual syndrome in adolescent school girls in Quetta, Pakistan.

\section{Materials and Methods}

A cross-sectional study was designed to explore information from 450 randomly selected adolescent girls. The respondents ranging from 12 to 16 years age, from 5 different government schools of Quetta, Baluchistan, Pakistan were briefed about close-ended questionnaires after taking their consent. Prior to data collection, pilot study was also conducted in order to evaluate feasibility. The questionnaires comprised information regarding the menarche, dysmenorrhea, food preferences, mood fluctuations, type of napkins used, menstrual hygiene, effect of physical activities, bathing etc symptoms which were commonly faced by girls during menstruation period. The collected data was analyzed by statistical software SPSS version 20. Associations of variable factors were calculated by chi-square test.

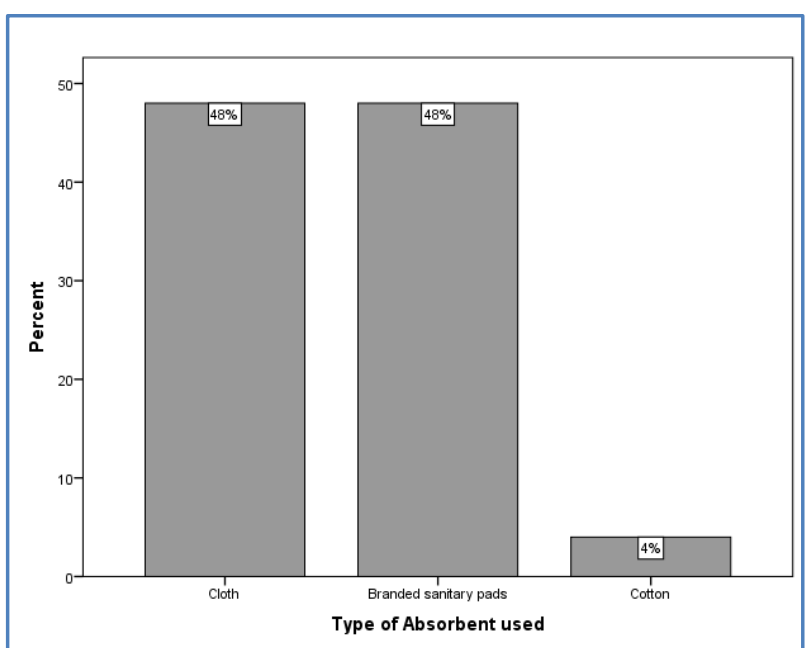

Figure 2 Variety of aids used as absorbents for menstrual bleeding. 
Table 1Association between different variables analyzed by chi-square test.

\begin{tabular}{|lc|}
\hline Association between two variables & $\mathrm{p}$-value \\
\hline Type of pain and amount of blood flow & $0.000(\mathrm{p}<0.05)$ \\
\hline Amount of blood flow and weakness & $0.000(\mathrm{p}<0.05)$ \\
\hline Regularity of menstruation and dysmenorrhea & $0.463(\mathrm{p}>0.05)$ \\
\hline Food and nausea & $0.003(\mathrm{p}<0.05)$ \\
\hline
\end{tabular}

\section{Results and Discussion}

Among the studied 450 respondents, the mean age of menarche was 12.5 years. Results of present study are in agreement with the study conducted by Dasgupta \& Sarkar (2008) and reported the age of menarche was 12.8 years. Similar types of results were also reported by Khanna et al. (2005). Results of present study revealed the effect of guidance on appropriate knowledge about personal hygiene for menarche and menstruation (Figure 1), mothers were found to be the main source of guidance $(55.11 \%$ cases), sisters $(30.22 \%)$, and friends $(12.22 \%)$ while only $2.44 \%$ get informed by relatives. The results were similar to Dasgupta \& Sarkar (2008) who reported mothers to be the first informants followed by friends and relatives. Similar findings were reported by Khanna et al. (2005) in Rajasthan, India and El-Gilanya et al. (2005) in Egypt.

The results of this study suggested equal use of cloth (48\%) and branded sanitary pads (48\%) while the remaining $4 \%$ preferred the cotton as absorbent (Figure 2). The observations of Zegeye et al. (2009) were similar to the findings of present study where as the findings of Moaweds (2001) were contradictory to the findings of this study, these researchers reported that $98.5 \%$ of the Pakistan and Indian girls were used to wear old cloth materials as sanitary napkin for blood absorption.

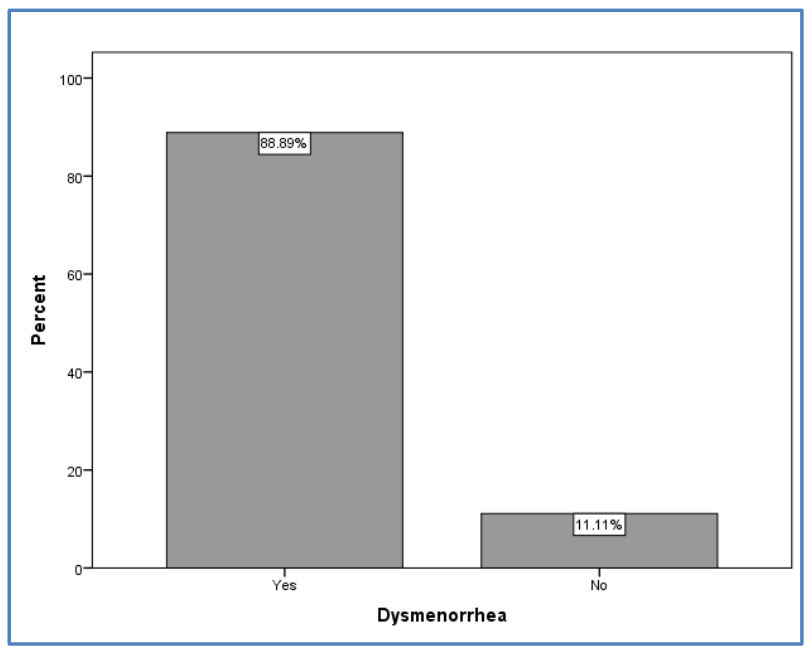

Figure 3 Prevalence of dysmenorrhea
Further, it was reported that severe abdomen pain was experienced by $44 \%$ girls who were having heavy menstrual flow, mild pain was experienced by $12 \%$ girls having comparatively light flow and the remaining (44\%) individuals had a moderate pain and moderate blood flow. Association between type of pain and amount of flow was found significant $(\mathrm{p}<0.05)($ Table 1$)$.

Current study revealed that the mean duration of blood flow in $48 \%$ cases was 5-7 days. The studies conducted by Zegeye et al. (2009) and Ali et al. (2011) found the mean duration of menstrual blood flow was $4 \pm 1.2$ days. Current results showed that weakness was also associated with amount of flow ( $\mathrm{p}<$ 0.05)(Table 1). The study of Roberts et al. (2003) also reported heavy bleeding as cause of weakness among girls.

The outcomes of the present analysis indicate that, dysmenorrhea was prevalent in most cases $(88.89 \%)$ (Figure 3).Similar results was obtained by Zegeye et al. (2009), they reported the prevalence of dysmenorrhea in $72 \%$ cases. Result suggested that $73 \%$ girls showed premenstrual symptoms. No association was found between dysmenorrhea and regularity (p>0.005) (Table 1). Al-Kindi \& Al-Bulushi (2011) also reported that there is no significant association between dysmenorrhea and regularity of cycle.

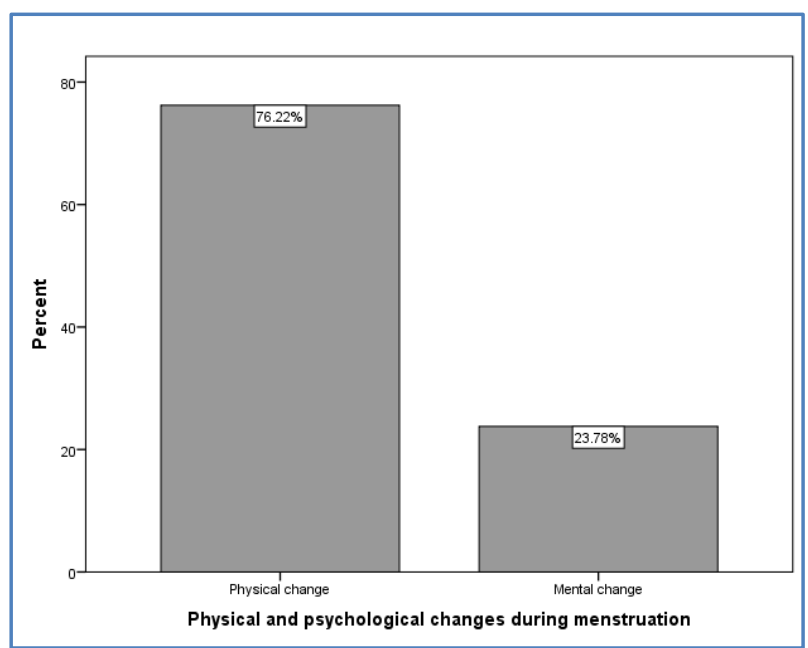

Figure 4 Physical and psychological changes during menstruation. 


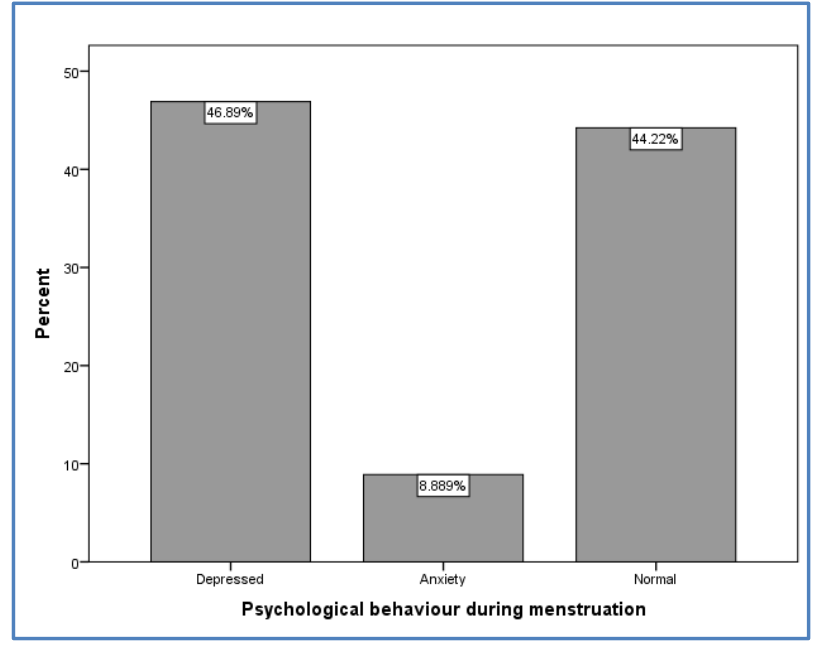

Figure 5 Psychological effects of menstruation.

Variable physical and psychological changes were also experienced during menstruation, $76.22 \%$ of the subjects suffered physical changes such as enlargement of hips, weight gain, swelling in legs etc. and $23.78 \%$ of them underwent psychological changes like depression and anxiety (Figure 4). Similar findings were also reported by Parsons \& Sammers (1978), Jarrett et al. (1995), George \& Bhaduri (2002), Lee et al. (2006). These researchers suggested that physical and psychological changes during menstruation were associated with dysmenorrhea. The findings of the present study regarding psychological behavior indicated that $46.89 \%$ subjects complained depression, $8.89 \%$ anxiety and the rest of $44.22 \%$ remained normal during menstruation (Figure 5). A statistically significant association between nausea and food was observed $(\mathrm{p}<0.05)$ (Table 1). Similarly, Wentz (1988) noted that, during menstruation dysmenorrhea was also the cause of sickness, headache, nausea, diarrhea and vomiting. Regarding the food habit during period, present survey concludes that $74 \%$ respondents prefer variety of food, vegetables and meat. Only $11 \%$ preferred to drink milk. Dasgupta \& Sarkar (2008) reported that $50 \%$ girls avoid certain foods during menstruation; in this manner their study is contradictory to the findings of present study.

Although, the condition of majority of participants remained normal but due to taboos, the majority $(61.11 \%)$ was hesitated to perform any physical activity, only $38.89 \%$ girls took partin activities like sports and exercise (Figure 6). Lee et al. (2006) reported that physical activity has no relationship with menstrual disorders. Similar results have been shown by Parsons \& Sammers (1978).

\section{Conclusion}

It is concluded from the study that dysmenorrhea was strongly prevalent. The majority of girls avoid physical activities like sports and exercise. Significant association $(\mathrm{p}<0.05)$ was also

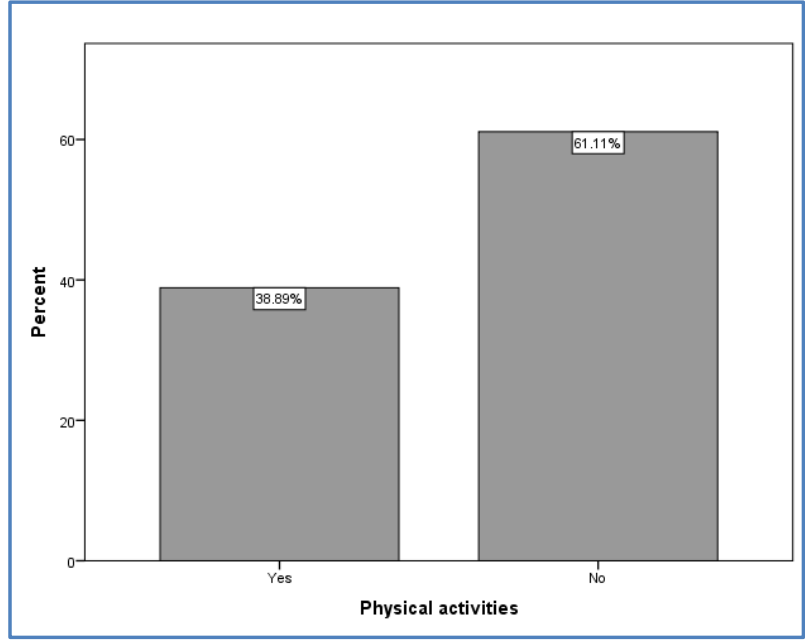

Figure 6 Participation of respondents in physical activities (during menstruation).

reported between food and nausea, amount of flow and weakness, type of pain and amount of flow. The mean duration of blood flow was 5-7 days. Depression and anxiety were also found among the girls who remained psychologically disturbed during this period.

\section{Acknowledgement}

Authors would like to thanks all the subjects who participated in the study.

\section{Conflict of Interest}

Authors would hereby like to declare that there is no conflict of interests that could possibly arise.

\section{References}

Agarwal AK, Agarwal A (2010) A study of Dysmenorrhea during Menstruation in Adolescent Girls. Indian Journal of Community Medicine 35:159-164 DOI: 10.4103/09700218.62586

Ali A, Rayis DA, Mamoun M, Adam I (2011) Age at menarche and menstrual cycle pattern among schoolgirls in Kassala in eastern Sudan. Journal of Public Health and Epidemiology 3:111-114

Al-Kindi R, Al-Bulushi A (2011) Prevalence and Impact of Dysmenorrhoea among Omani High School Students. Sultan Qaboos University Medical Journal 11: 485-491 PMCID: PMC3206751

Dasgupta A, Sarkar M (2008)Menstrual Hygiene: How Hygienic is the Adolescent Girl? Indian Journal of Community Medicine 33:77-80 DOI: 10.4103/0970-0218.40872 
Dawn CS (1990) Textbook of Gynaecology and Contraception. 10th edition. Dawn Books, Calcutta, India

Diaz A, Laufer MR, Breech L (2006) Menstruation in girls and adolescents: Using the menstrual cycle as a vital sign. Pediatrics 118: 2245-2250

El-Gilanya A, Badawib K, EL-Fedawyb S (2005)Menstrual hygiene among adolescent school girls in Mansoura, Egypt. Reproductive Health Matters 13:147-152 PMID: 16291496

George A, Bhaduri A (2002) Dysmenorrhea among adolescent girls - symptoms experienced during menstruation. Health Promotion and Education 17:4.

Jarrett M, Heitkemper MM, Shaver JF (1995) Symptoms and self-care strategies in women with and without dysmenorrhea. Health Care for Women International16:167-78 PMID: 7759347

Kaplowitz P (2006) Pubertal development in girls: Secular trends. Current Opinion in Obstetrics and Gynecology 18:487491PMID: 16932041

Khanna A, Goyal RS, Bhawsar R (2005) Menstrual practices and reproductive problems: a study of adolescent girls in Rajasthan. Journal of Health Management 7:91-107

Lee LK, Chen PCY, Lee KK, Kaur J (2006) Menstruation among adolescent girls in Malaysia: a cross-sectional school survey. Singapore Medical Journal 47:869-874 PMID: 16990962.
Moaweds S (2001) Indigenous practices of Saudi girls in Riyadh during their menstrual period. Eastern Mediterranean Health Journal 7:197-203PMID: 12596970

Parsons L, Sammers S (1978) Gynecology. 2nd edition. Philadelphia: WB. Saunder's Company, 42-5

Paul D (2007) A report of an ICMR funded research project: Knowledge and practices of adolescent girls regarding reproductive health with special emphasis on hygiene during menstruation. New Delhi: National Institute of Public Cooperation and Child Development (NIPCCD)

Roberts TA, Glen J, Kreipe RE (2003) Disordered eating and menstrual dysfunction in adolescent female athletes participating in school-sponsored sports. Clinical Pediatrics (Philadelphia) 42:561-564

Shersha, Syed, John JM, Sadiqa J (1991) Prevalence of premenstrual syndrome in Pakistani women. Journal of the Pakistan Medical Association 41:101-103

Wentz AC (1988) Dysmenorrhoea, Premenstrual syndrome and related disorders. Novak's textbook of Gynaecology. Baltimore: Williams and Wilkins, 240-60

Zegeye DT, Megabiaw B, Mulu A (2009) Age at menarche and menstrual pattern of secondary school adolescents in northwest Ethiopia. BMC Women's Health 9: 29 DOI: $10.1186 / 1472-6874-9-29$

Ziv A, Boulet JR, Slap GB (1999) Utilization of physician offices by adolescents in the United States. Pediatrics 104:3542 